\title{
PREVALENCE AND CHEMOTHERAPY OF TRICHOSTRONGYLOIDS IN CAMELS IN CHARSADA
}

\author{
MUHAMMAD QASIM ${ }^{1}$; AZHAR MAQBOOL ${ }^{1}$; MUHAMMAD IJAZ ${ }^{2}$; \\ ABRAR AHMAD ${ }^{3}$ and AHMED DYAB ${ }^{4}$ \\ ${ }^{1}$ Department of Parasitology, University of Veterinary and Animal Sciences, Lahore. \\ ${ }^{2}$ Department of Clinical Medicine and Surgery, University of Veterinary and Animal Sciences, Lahore. \\ ${ }^{3}$ Department of Veterinary Pharmacology Sindh Agriculture University Tandojam \\ ${ }^{4}$ Department of Parasitology Faculty of Medicine Assiut University Egypt
}

Received: 31 December 2016; $\quad$ Accepted: 19 January 2017

\begin{abstract}
The prevalence of Ttrichostrongyloids among camels in Charsada district was measured and trials conducted to determine the efficacy of Saussurea lappa and Fumaria parviflora and Albendazole. 500 camels were examined, and trichostrongyloids were observed in 175 (35\%). Haemonchos longisteps was the most predominant specie with the prevalence of (52.57\%), followed by Trichostrongylus probolurus, Ostertagia Ostertagi, Dictyocaulus and Nematodirus dromedari being $10.85 \%, 9.71 \%, 9.14 \%$ and $9.14 \%$ respectively. Cooperia was found to be the least prevalent $8.57 \%$ parasite. Young animals were found to be at higher risk of infection than adult animals. The efficacy of Saussurea lappa was $65.85 \%$, Fumaria parviflora was 46.34 , and albendazole was $(66.66 \%)$ at one dose. Whereas the efficacy after second dose was of Saussurea lappa (85.36\%), Fumaria parviflora was $(82.92 \%)$, and albendazole was $(97.43 \%)$. Making albendazole is the most effective treatment against trichostrongyloids in camels.
\end{abstract}

Key words: Trichostrongyloids, prevalence, chemotherapy, camel.

\section{INTRODUCTION}

Camels play an important role in the socioecnomic system of Asia and Africa. Pakistan beingthe third one among the camel rearing countries in the world having 1.2 million Dromedary camels (FAO 2000), with an annual increase of $1.62 \%$ (Ashraf et al., 2014). In camel, parasitic diseases causes huge economic losses, in terms of low production and medication cost. The camels are infected by a large number of internal parasites including, Heamonchus and Trichostrongylus. The Heamonchus causes Haemonchosis which is the most common pathogenic infection with almost $100 \%$ morbidity. Symptoms include emaciation, anemia, and oedema of lower limbs, eosinophilia, hypoproteinemia and hypoalbuminemia. Pica is associated with haemonchosis and worm infections in camels. Trichostrongylus spp. may contribute to the debilitating effects. Anemia is one of the pathogenic effects of gastrointestinal parasites (Soulsby, 2006). These Helminths produces lesions which could reduce the productivity of the infected dromedary

Corresponding author: Dr. AHMED DYAB

E-mail address: Ahmedsaf2001@yahoo.com or ahmed2015@aun.edu.eg.

Present address: Department of Parasitology Faculty of Medicine Assiut University Egypt through disturbance of intestinal absorption (McGavin and Zachary 2007). Diseasestates of infestation results in reduce production of wool and meat by losing appeptite and poor consumption of nutritional substances, which may lead to low fertility, abortion and death (Windsor et al., 1992). Ethnoveterinary practice includes all the traditional methods and indigenous knowledge usefull for the maintenance of livestock health and production (Wanzala et al., 2005). Modern allopathic drugs are usually expensive and unavailable in far flung areas of many communities and people mostly depend on ethnoveterinary practice to solve such problems (Kumar, 2007 and Chafe et al., 2008). The present study was therefore launched aiming to evade the prevalence of Trychostrongyloids in camels of Charsadda as there is very scanty information available on helminthes infection in camels (Bekele2002) and the comparative efficacy of two medicinal plants (saussurea lappa and Fumaria parviflora) and an allopathic drug (Albendazole).

\section{MATERIALS AND METHODS}

\section{Experimental Design}

500 fecal samples were collected from camels in and around Charsada for trichostrongyloids. The samples were examined at Veterinary Research Institute Peshawar. All animals were kept under similar 
feeding and managemental conditions throughout the course of treatment. The studies were conducted during late summer months. A detailed history of each individual animal was recorded.

\section{Animal utilized}

Animals were casually arranged into 4 groups i.e. A, $\mathrm{B}, \mathrm{C}$ and D with 15 camels in each group. In group A and B animals were treated with Sussurea lappa (Qust-e-shireen) @60mg/kg body weight, and Fumaria parviflora (shahtra) @60mg/kg body weight respectively. While the animals in group $\mathrm{C}$ was treated with Albendazole at dose rate of $10 \mathrm{mg} / \mathrm{kg}$ body weight and group D was kept as negative control. Efficacy of drug was calculated as described by Varady et al. (2004).

\section{Preparation and administration of drugs}

The herbal preparations were dried, finely ground to powder form and stored in sealed glass bottles at 4 ${ }^{\circ} \mathrm{C}$. Gum tragacanth was also finely powdered and a $2 \% \mathrm{w} / \mathrm{v}$ aqueous solution was prepared and stored in a refrigerator at $4{ }^{\circ} \mathrm{C}$. At the time of treatment, a calculated amount of herbal drugs were weighed according to recommended dosages and suspended in $100 \mathrm{ml}$ of $2 \%$ gum solution given P.O. Saussurea lappa and Fumaria parviflora were suspended in gum solution due to their lower solubility.

\section{Parasitological techniques}

The qualitative examination of faecal sample was done by light microscopy, sedimentation and flotation methods. While quantitave faecal inspection was done using Mac -Master (egg counting) technique as described by Souls by, 2006. Faeces were examined on day zero day and on day 3 rd, 7 th, and 18th post treatment (Maqbool et al., 2004). The effect of drugs on pregnancy, milk yield and body mass were also recorded along with side effect of drugs. Efficacy of drug was evaluated as described by Varady et al. (2004).

\section{RESULTS}

\section{Efficacy of Saussurea lappa}

In clinical cases EPG count of trichostrongyloids in camels treated with saussurea lappa show an accumulative tendency in control (untreated) animals. A single dose of $60 \mathrm{mg} / \mathrm{kg}$ body weight of Saussurea lappa show a decrease of $14.63 \%, 41.46 \%$ and $65.85 \%$ in EPG counts on the $3^{\text {rd }}, 7^{\text {th }}$, and 18 th day respectively.

\section{Efficacy of Fumaria parviflora}

Fumaria parviflora at $60 \mathrm{mg} / \mathrm{kg}$ dose cause a decrease of $12.19 \%, 31.70 \%$ and $46.34 \%$ in EPG counts on the $3^{\text {rd }}, 7^{\text {th }}$, and 18 th day, respectively.

\section{Efficacy of Albendazole}

Allopathic drug, i.e. albendazole, at the recommended dose of $10 \mathrm{mg} / \mathrm{kg}$ caused $12.82 \%$ reduction on the $3^{\text {rd }}$, $34.46 \%$ on $7^{\text {th }}$, and $66.66 \%$ on 18 th day.

Relative efficacy of all three drugs at their optimum levels on various days as compared with (day zero) showed that all drugs had a significant antitrichostrongyloids efficacy effect. The highest efficacy was shown by Albendazole and Saussurea lappa were $66.66 \%$ and $65.85 \%$ respectively, while efficacy of Fumaria parviflora was $46.34 \%$.

Table: 1: Overall Prevalence of Trichostrongyloids in camels.

\begin{tabular}{cccc}
\hline \multirow{2}{*}{ No of camels examined. } & Name of parasites & No of positive & $\%$ of infection \\
\hline 500 & Haemonchus longisteps & 92 & $52.57 \%$ \\
\cline { 2 - 4 } & Trichstrongylus probolurus & 19 & $10.85 \%$ \\
\cline { 2 - 4 } & Ostertagia ostertagi & 17 & $9.71 \%$ \\
\cline { 2 - 4 } & Dictyocaulus & 16 & $9.14 \%$ \\
\cline { 2 - 4 } & Nematodirus & 16 & $9.14 \%$ \\
\cline { 2 - 4 } & Cooperia & 175 & $35 \%$ \\
\hline
\end{tabular}

Table: 2: Efficacy in Percentage of various drugs against trichostrongyloids in camels at different days.

\begin{tabular}{lcccc}
\hline \multirow{2}{*}{ Drugs } & \multirow{2}{*}{$\begin{array}{c}\text { No of } \\
\text { Animals }\end{array}$} & \multicolumn{2}{c}{ Efficacy in percentage on different days } \\
\cline { 3 - 5 } & & \multicolumn{2}{c}{ First treatment (\%) } \\
\cline { 3 - 5 } Saussurea lappa & 15 & $3^{\text {rd }}$ & $7^{\text {th }}$ & $18^{\text {th }}$ \\
\cline { 3 - 5 } & 15 & 14.63 & 41.46 & 65.85 \\
\hline Fumaria parriflora & 15 & 12.19 & 31.70 & 66.34 \\
\hline Albendazole & & 12.82 & 34.46 & 66.66 \\
\hline
\end{tabular}




\section{DISCUSSION}

\section{Prevalence of Trichostrongyloids}

The overall results among camels in district Charsada Kpk, showed that among 500 (Total) 175 (35\%), were found positive. Six species which were identified are in order of intensity are Haemonchus longistipes, Trichostrongylus probolurus, Ostertagia ostertagi, Dictyocaulus, Nematodirus dromedari, and Cooperia. The high incidence of Haemonchus longistipes occur due to changes in grazing behaviour from feeding on upper bushes, to feeding on grasses, as a results of removal of bushes, shrubs and trees for rain fed mechanized crop production schemes. Thus increasing the chances of pitching up of ova and larvae from pasture was also reported by El Khouly and El-Khawad (2011). Abdul Salam and Farah (1988), Anwar (1987), Burji et al. (2010), Tajik et al. (2011). It was also noted that the overall incidence of endoparasites was higher in younger animals than adults this was supported by Swai et al. (2011). They reported that younger animals can act as source of infection for adults. It was reported that overall infection was higher in females than males; this was in line with Steward (1950), Raisin ghani (1992) and Sharrif et al. (1997). It has shown that rate of infection in the present study was nearly similar to the above stated workers in various regions throughout the world. However Abu-Bakr et al. (2000), Arzoun et al. (1984), Burji (2010), Bamaiyi and Kalu (2012), Banaja and Ghandur (1994), Bakele (2002), Bihari and Kawasmeh (1980), Kayum et al. (1992), Parsani et al. (2008) and Raza et al. (2007) recorded diverse prevalence in different countries of the world. These findingsare somewhat in consistency with the results of the present study; the change may be due to diverse geographical regions and varied environmental conditions.

\section{Chemotherapy}

For the operative chemotherapy and intentional chemoprophylaxis of endoparasites of camels, a safe drug is required with high activity against all stages of parasites. Modern drugs are efficacious but most of them possess adverse effects, Rewatkar (2008), thus marketing of new, highly therapeutic and cheap drug can contribute to the field of research. The antiparasitic activity of indigenous drugs including Saussurea lappa and Fumaria parviflora were evaluated for their comparative efficacies with each other and with modern allopathic drug i.e. Albendazole.

Saussurea lappa (Qust-e-shireen) at $60 \mathrm{mg} / \mathrm{kg}$ body weight was 65.85 percent effective at single dose. Similar findings were also reported by Kailani et al. (1995), Itty et al. (1997), Waller and Prichard (2001), Maqbool et al. (2004) and Stafford and Coles (2007).
Efficacy of Fumaria parriflora at $60 \mathrm{mg} / \mathrm{kg}$ body weight was $46.34 \%$ effective at one dose level. Nearly similar results were recorded by Akhter and Javed (1985). Akhter and Farah (1986), and Waller and Prichard (2001), Maqbool et al. (2004), Stafford and Coles (2007) reported that this drug contain $40 \%$ alkaloid which might be its active ingredient the high efficacy or reduction in the parasite burden may be due to its active ingridient. It was concluded that Fumaria parriflora at dose rate of $60 \mathrm{mg} / \mathrm{kg}$ body weight give good result for the treatment of various endoparasitic infections in camels.

Albendazole was given to camels at recommended dose rate i.e. $10 \mathrm{mg} / \mathrm{kg}$ body weight and caused 66.66 percent reduction in EPG count. Similar results were also showed by various workers in various parts of the world as Al Qudah et al. (1998), Akhterand Javed (1991), and Varady et al. (2004).

\section{Conflict of interest}

The authors have no conflict of interest regarding this research work.

\section{Ethical Statement}

The animals and human rights were not violated or ignored. All the participants were assigned on their well with signing consent before inclusion into the study.

\section{REFERENCES}

Abdul-Salam, J. and Farah, M. (1988): Seasonal fluctuations of gastrointestinal helminths of camels in Kuwait. Vet Parasitol. 28 (1): 93102.

Abubakr, M.; Nayel, M.; Fadlalla, M.; Abdelrahman, A.; Abuobeida, S. and Elgabara, Y. (2000): Prevalence of gastrointestinal parasites in young camels in Bahrain. Revued Elevage Et De Medicine Veterninaire Des Pays Tropicaux. 53 (3): 267-272

Akhter, MS. and Javed (1985): Efficacy and safety of saussurea lappa and fumaria parviflora against Neo-ascarisvitolerum in buffalo, calves. Pak vet. J. 5 (4):153-158.

Akhter, MS. and Javed (1991): Efficacy of herbal drugs against Moniezia infection in sheep. Indian Vet. J. 68: 726-729.

Akhter, MS. and Farah, N. (1986): Phyto chemical screening of morusalba, Nigella sativa and fumaria parviflora. J. pharmaunikarachi 5:914.

Al-Qudah, K.; Sharif, L.; Al-Rawashdeh, O. and AlAni, F. (1998): Efficacy of Closantel Plus Albendazole Liquid Suspension against Natural Infection of Gastrointestinal Parasites in Jordanian Camels. In: Proceedings of the Third Annual Meeting for Animal Production Under Arid Conditions, vol. 1: 150-159. 
Anwar, M. (1987): A study on the prevalence of gastrointestinal parasites of one-humped camel (Camelus dromedarius). M. Sc. Thesis, Department of Veterinary Parasitology, University of Agriculture, Faisalabad.

Arzoun, I.; Hussein, H. and Hussein, M. (1984): The prevalence and pathogenesis of naturallyoccurring, Haemonchus longistipes, infection in Sudanese camels. Journal of comparative pathology. 94 (2): 169-174.

Ashraf, S., H. .Chaudhry, R M. Chaudhry, Z. Iqbal, M. Ali, T. Jamil, N. Sial, M. I. Shahzad, F. Basheer, S. Akhter, S.H. U. Rehman and A. Yasin (2014). Prevalence of common diseases in camels of Cholistan Desert, Pak. J. Inf. Mol. Biol: 2: 49 - 52 .

Bamaiyi, PH. and Kalu, AU. (2012): Gastrointestinal parasites infection in one-humped camels (Camelus dromedarius) of Nigeria. In: Veterinary Research Forum, vol. 2: 278-281.

Banaja, A. and Ghandour, A. (1994): A Review of Parasites of Camels (Camelus dromedarius) in Saudi Arabia. Science. 6 (1): 75-86.

Bekele, T. (2002): Epidemiological studies on gastrointestinal helminthes of dromedary (Camelus dromedarius) in semi-arid lands of eastern Ethiopia. Vet Parasitol. 105(2): 13952.

Bihari, SE. and Kawasmeh, Z. (1980): Occurrence and seasonal variation of some gastrointestinal helminths of the dromedary, Camelus dromedarius, in Saudi Arabia. In: Proceedings of the Fourth Conference on the Biological Aspects of Saudi Arabia: University of Riyadh .297-304.

Burji, H.; Razmi, G.; Movassaghi, AR.; Naghibi, AG. And Maleki, M. (2010): A study on gastrointestinal helminths of camels in Mashhad abattoir, Iran. Iran J. Vet. Res. 11 (2): 174-179.

Chafe, U.M.; Musa, A. and Dogara, B. (2008): Studies of some health aspects of traditional camel management in North West Nigeria. Livestock Research for Rural Development, Vol. 20, Article No 31, Retrieved.

El-Khouly, F. and El-Khawad, A. (2011): Priliminary survey of Helminth parasites in race camels in UAE. Emirates Journal of Food and Agriculture. 4 (1).

FAO (2000): FAO production Year Book VOL. 54 Food and Agriculture Organization of United Nations, Rome, Italy.

Itty, P.; Zinsstag, J.; Ankers, P.; Njie, M. and Pfister, $K$. (1997): Returns from strategic anthelmintic treatments in village cattle in the Gambia. Preventive Veterinary Medicine. 32 (3): 299310.

Kailani, SR.; Akhtar, MS. and Ashraf, M. (1995): Antifasciolic efficacy of indigenous plant drug: kalonji, shahterah and Karanjwa in buffaloes. Pak J. Pharm Sci. 8(1):17-27.

Kayum, A.; Afzal, M. and Salman, R. (1992): Gastrointestinal parasites in racing camels: prevalence and evaluation of different methods of faecal examination. In: Proceedings of the Ist. International Camel Conference, United Arab Emirates: 85-87.

Kumar, Y.D. (2007): Ethnoveterinary practices. A boon for indigenous cattle productivity in Gaushalas. Livestock Research for Rural Development, Vol. 19, Article No 75, Retrieved November 28, s2008 from http://www.cipav.org.co/lrrd19/6/kuma19075. htm.

Maqbool, A.; Hayat, CS. and Tanveer, A. (2004): Comparative efficacy of indigenous and allopathic drugs against fasciolosis in buffaloes. Veterinarshiarhiv 74 (2): 107-114.

McGavin, MD. and Zachary, JE. (2007): Pathologic basis of veterinary disease. $4^{\text {th }}$ Edn., St. Louis, Missouri, Mosby-Elsevier. PP: 388-389.

Parsani, H.; Singh, V. and Momin, R. (2008): Common parasitic diseases of camel. Vet World. 1 (10): 317-318.

Raisin, GPM. (1992): Helminthic diseases of dromedary camel in India. Proc are tint camel conf. 105-106.

Raza, MA.; Iqbal, Z.; Jabbar, A. and Yaseen, M. (2007): Point prevalence of gastrointestinal helminthiasis in ruminants in southern Punjab, Pakistan. J. helminthol. 81 (3): 323.

Rewatkar, S.; Deshmukh, S.; Deshkar, S.; Maske, D.; Jumde, P. and Bhangale, G. (2008): Gastrointestinal helminths in migratory Camel. 75(3) 86-91.

Sharrif, L.; AlQudah, K. and AlAni, F. (1997): Prevalence of gastro-intestinal helminths in one-humped camels (Camelus dromedarius) in Jordan. Journal of Camel Practice and Research. 4 (1): 67-69.

Soulsby, EJL. (2006): Helminthes, arthropods and protozoa of domesticated animals $7^{\text {th }} \mathrm{Ed}$ baillieretindall, London. 686-687.

Stafford, M. and Coles, E. (2007): Anthelminthic resistance in cattle. Vet. Rec. 160 (19): 671672.

Steward, J. (1950): Notes on some parasites of camels (Camelus dromedarios) in the Sudan. Veterinary Record. 62 (52): 835-837.

Swai, E.; Moshy, W.; Mashanga, J. and Bwanga, S. (2011): Intestinal parasitic infections of camels in the agro and pastoral areas of northern Tanzania. Vet. Res. 4 (2): 34-38.

Tajik, J.; Moghaddar, N.; Nikjou, D. and Taleban, Y. (2011): Occurrence of gastrointestinal helminths in Bactrian camel in Iran. Trop. Biomed. 28 362-365

Varady, M.; Konigova, A. and Corba, J. (2004): A field study to evaluate the efficacy of 
Fenbendazole on 9 stud farms. Vet. Med. Czech. 49: 42-46.

Waller, P.J. and Prichard, RK. (2001): Drug resistance in nematodes in chemotherapy of parasitic infections W C Cambell and R.S reweds plenum New York.

Wanzala, W.; Zessin, K.H.; Kyule, N.M.; Baumann, M.P.O.; Mathias, E. and Hassanali, A. (2005):
Ethnoveterinary medicine: a critical review of its evolution, perception, understanding and the way forward. Livestock Res. Rural Dev., $17: 1-31$

Windsor, RS.; Windor, RHS. And Teran, M. (1992): Economic benefits of controlling external and internal parasites in South American Camelids. Annals, N Y Acad Sci. 16: 398-405.

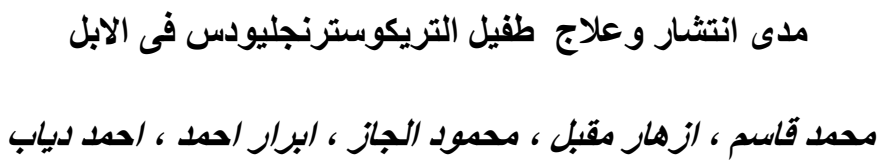

Email: Ahmedsaf2001@yahoo.com Assiut University web-site: www.aun.edu.eg

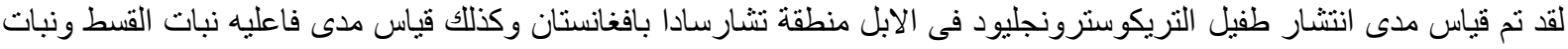

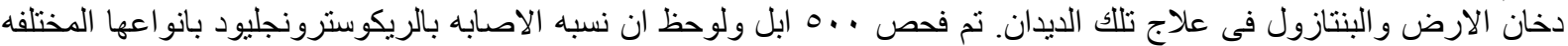

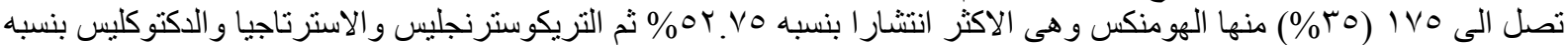

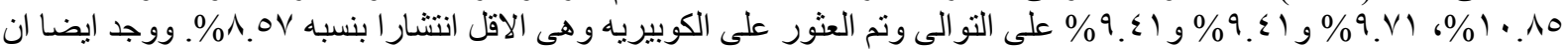

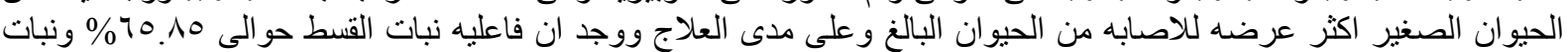

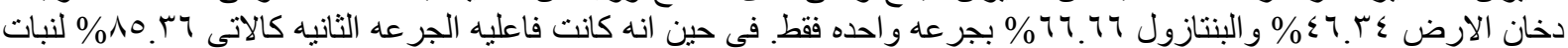

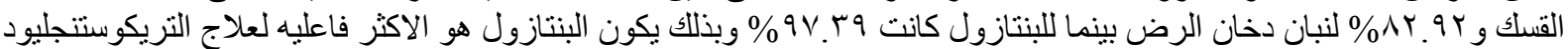

